\title{
Erratum
}

\section{Activation Characteristics of the Calcium-Dependent Outward Potassium Current in Helix}

\author{
H. D. Lux and G. Hofmeier \\ Abteilung Neurophysiologie, Max-Planck-Institut für Psychiatrie, Kraepelinstrasse 2, D-8000 München 40, Federal Republic of Germany
}

Pflügers Arch (1982) 394: 70-77

The abstract should read as follows:

\begin{abstract}
The activation of calcium-dependent outward potassium current $\left[\mathrm{I}_{\mathrm{K}(\mathrm{Ca})}\right]$ by shortlasting $\mathrm{Ca}^{2+}$ inward currents was studied. These $\mathrm{Ca}^{2+}$ currents were produced either by small depolarizing pulses preceding the larger depolarizations or by interposed repolarizations (I.R.s) starting from depolarized membrane potentials. $I_{K(C a)}$ then develops with a potential-invariant time course (half time $6-12 \mathrm{~ms}$ ) and the normally bell-shaped isochronal $\mathrm{I}_{\mathrm{K} \text { (Ca) }} / \mathrm{V}$ curve, measured at between 30 and $300 \mathrm{~ms}$, is straightened. However, these $\mathrm{Ca}^{2+}$. injecting pulses, of any amplitude and duration, do not increase the steady-state conductance to values beyond those measured with single step depolarizations to lower potentials. Once activated after a prepulse, $\mathrm{I}_{\mathrm{K}(\mathrm{Ca})}$ is maintained also during depolarization to near the supposed calcium equilibrium potential with no further $\mathrm{Ca}^{2+}$ influx. When I.R.s are varied in length, activation of $I_{K(C a)}$ increases linearly with the amount of $\mathrm{Ca}^{2+}$ current. Fading of activation during I.R. follows a time course nearly ten times slower than activation and is not expressed in tail currents. The time course of $I_{K\left(C_{a}\right)}$ is described by a function defined only by voltage parameters of activation combined with a minimum activation time constant which is similar to that found in tail currents. Peak location and general form of the $I_{K_{(C a)}} / V$ relationship for times up to several hundred milliseconds are well predicted without the necessity to explicitly account for actual calcium entry.
\end{abstract}

